\title{
LA NOSTALGIA DE LOS TRABAJADORES MIGRANTES DE LA CONSTRUCCIÓN: REFLEXIONES SOBRE SALUD \\ MENTAL
}

HOMESICKNESS AND MIGRANTS WORKERS: REFLECTIONS ABOUT THE MENTAL

HEALTH

Marina Batista Chaves Azevedo de Souza ${ }^{1}$ y Barbara lansã de Lima Barroso²

\begin{abstract}
Resumen
Los sentimientos de añoranza surgieron en las entrevistas, y el artículo tiene como objetivo caracterizar en el contexto público, lo que permite reflexiones sobre las posibles relaciones con la experiencia de duelo o pérdida transitoria; aspectos que, además similares a los sentimientos de ausencia y directamente vinculado a los migrantes. El estudio es descriptivo, con un enfoque cuantitativo y cualitativo, analizado a partir del método de análisis de contenido, basado en un paradigma interpretativo. No podría decir que en el contexto de los encuestados, la presencia de este sentimiento está desarrollando a situaciones profundas / melancólica tristeza. Sin embargo, una asimilación más consciente de ese sentimiento a lo largo para ayudar a la integración de los trabajadores en los dispositivos de socialización disponibles, contribuiría a una mejor incorporación de los individuos a la cultura local y la reducción de los posibles daños a largo plazo.
\end{abstract}

\section{Palabras clave}

Migración; la salud del trabajador; nostalgia; terapia ocupacional.

\section{Abstract}

Feelings of longing emerged in the interviews, and the article aims to characterize them in the audience context, enabling reflections about possible relations with the experience of bereavement or transient loss; aspects that besides similar to the feelings of absence and directly linked to migrants everyday can be influencers of mental health. The study is descriptive, using a qualitative and quantitative approach, analyzed from the content analysis method, based on an interpretative paradigm. It was found that the longing and grief, are recurrent for workers. Could not say that in the context of respondents, the presence of this feeling is developing to deep / melancholy sadness situations. However, a more conscious assimilation of that feeling along to aid the integration of workers in socialization devices available, would contribute to better incorporation of individuals to local culture and reduction of possible long-term damage.

\section{Keywords}

Migration; worker health; longing; occupational therapy.

Recepcionado: 30/03/2017

Aceptado: 19/06/2017 


\section{INTRODUÇÃO}

Este estudo é parte da linha de pesquisa 'Trabalho, migração e contextos de vida do operariado' do Laboratório de Saúde, Trabalho e Ergonomia (LASTE) d Universidade Federal da Paraíba (UFPB). Representa uma secção de um projeto maior de averiguação do perfil de trabalhadores migrantes da construção civil em João Pessoa/PB, no nordeste brasileiro, e das características de suas atividades de trabalho. Depois de analisar a rotin de trabalho e de vida dos indivíduos, os pesquisadores reconheceram, em suas falas, a presença constante do sentimento de saudade, questão que será abordada como tema central neste artigo.

De acordo com Six (2007), o crescimento econômico nacional, associado à multiplicação e à diversificação dos postos de trabalho, fomenta a migração pendular, particularmente incitada pelas dimensões geográfica do Brasil e pela maciça concentração de investimentos em setores específicos, como a construção civil, nas capitais brasileiras.

Para Assis, Franken, Meneses e Oliveira (2013), é criada uma zona de empatia entre o crescimento econômico e o desejo de se melhorar de vida, que não se restringe à busca por alimento e abrigo, porquanto também inclu condições de moradia, educação, saúde e lazer

Devido à necessidade de atender às demandas voltadas para melhorar sua vida, os trabalhadores migrantes abrem mão do cotidiano em sua cidade natal, localizada no interior da Paraíba, migram para a capital do estado da Paraíba e alocam-se semanalmente nos alojamentos disponibilizados pelas empresas da construção civil.

Assim, o objetivo geral deste estudo foi o de caracterizar a saudade no contexto do público-alvo, viabilizando reflexões acerca das possíveis relações desses sentimentos com os sentimentos de luto e perda transitória e pos síveis implicações na saúde mental dos trabalhadores entrevistados.

De acordo com Andrade e Cardoso (2012) ${ }^{3}$, a relevância social desse tipo de pesquisa está relacionada aos grandes índices de afastamento do trabalho proveniente de transtornos mentais. A escolha por desenvolver a pesquisa no setor da construção civil se justifica porque ela é marcada por uma diversidade de atividades que ocorrem ao mesmo tempo e absorvem ampla quantidade de mão de obra. Esse contexto é um grande influenciador da sociedade, devido aos seus impactos na economia nas organizações e na Previdência Social. Dados do Anuário Estatístico da Previdência Social brasileira indicaram que, em 2015, a construção civil foi o terceiro setor econômico com o maior número de acidentes de trabalho (Brasil, 2013).

\section{Saudade (homesickness) e movimentos migratórios}

Bhugra e Becker (2005) definem a saudade, no contexto da migração, como a falta de contato com a terra natal e com tudo o que dela provém. Esses aspectos são undamentais para se construir a identidade do homem.

Noriega (2009) assevera que as atitudes das sociedades para onde os indivíduos migraram (como o racismo) e o estresse por causa do medo de iniciar um novo trabalho em uma cultura diferente podem causar sofrimento psíquico.

Ao falar sobre o movimento migratório, Borges e Martins (2004) referem que essa experiência é uma noção da fragmentação de uma identidade, pois a perda do referencial conhecido gera uma experiência de desamparo que pode ser vivida e associada ao abandono. Os sentimentos de saudade ou de abandono podem ou não se encaminhar para experiências negativas, a depender das próprias experiências do passado do sujeito.

A saudade pode ser considerada pela Psicanálise como um sentimento que reproduz a sensação de perda do "objeto" (aquilo que tem importância na vida do indivíduo), ou seja, de um luto transitório (no caso da migração). Essas sensações podem evoluir para o desenvolvimento de psicopatologias, como a melancolia, por exemplo.

Canha (2009), no fragmento a seguir, procura diferenciar o luto da "melancolia" e o desenvolvimento de psicopatologias.

\begin{abstract}
A melancolia, hoje chamada de depressão é a reação à perda do objeto amado, sendo que esse não precisa ter morrido, necessariamente (...), teoria segundo a qual se permite compreender a relação entre migração e depressão. Essa perda pode ser notada mesmo que não se saiba ao certo o que se perdeu (Canha, 2009, p. 25) .
\end{abstract}

O luto, ainda considerado nessa perspectiva, é uma fase transitória e não patológica, em que o sujeito se depara com a perda do objeto de amor - a saudade. Essa fase é superada quando se substitui o amor ao objeto perdido pelo amor a outros objetos (Freud, 1920). Klein (1971) afirma que, no luto normal, o sujeito consegue reestabelecer o objeto amado, e na melancolia, essa 
reorganização fracassa. Quando os sentimentos de luto são associados à saudade e recorrentes dos processos de migração, à luz da Psicanálise, podem ser substituídos pela penetração do migrante na nova sociedade, e aos grupos e dispositivos sociais presentes nesse novo ambiente.

\section{Migração pendular}

Branco, Firkowski e Moura (2005) conceituam a mobilidade pendular como o movimento dos indivíduos que residem em determinada cidade ou município, mas que, por algum motivo, necessitam cumprir suas atividades de trabalho em um local diferente. Ao analisar esse movimento, percebemos que esse tipo de migrante está, na maioria das vezes, em busca de relação com um município que dispõe de melhor economia, de capital de giro e de oportunidades de emprego.

De acordo com dados do Instituto de Pesquisa Econômica Aplicada, em 2008, no Nordeste, 61,5\% dos migrantes executavam trabalhos informais (BRASIL, 2010). Essa informalidade diminuiu em relação aos anos de 1995 (70,3\%), 2001 (70\%) e 2005 (63,7\%). Quanto ao salário dos migrantes no NE, também aumentou desde 1995 - era estimado em R\$928,42 e passou, em 2008, para $R \$ 1.092,71$. A partir desse fato, no Brasil, houve transformações substantivas no trabalho.

Quando o deslocamento pendular se resume ao fato de voltar com o dinheiro com que sustenta a família, os grupos de trabalhadores da indústria civil se isolam ao redor dos alojamentos. Eles são denominados por Hunger, Rossi e Souza (2015) de outsiders, que representam os intrusos, recém-chegados, ou migrantes que, muitas vezes, são inferiorizados e estigmatizados pelos já estabelecidos. Os guetos dilaceram as possibilidades de os migrantes se apropriarem da cultura local.

Estudos de Jabur, Campos, Souza e Paula (2014) constataram que a migração é um processo de ruptura social muito evidente nas entrevistas com migrantes. Assim, não são somente o conjunto e a natureza de laços sociais que se desfazem abruptamente, mas também a maneira como esses fiapos de relação, vínculo, realidade e sentimentos de saudade são vivenciados.

Pusseti (2015) descreve a saudade como oriunda do deslocamento, causadora de uma possível "psicopatologia" identificada no migrante, que seria o resultado da passagem árdua de uma cultura para outra, da falta de integração na sociedade de acolhimento, da crise identitária, da discriminação. Assim, constantemente, constata-se que faltam o referencial da cidade natal ou os sentimentos de saudade, não apenas como incitadores de processos patológicos, mas também como dependentes da história pregressa do indivíduo e sua relação com a perda e o abandono.

No que diz respeito às características dos migrantes brasileiros na construção civil, como os participantes desta pesquisa, o grande número desses operários pode ser explicado pela peculiaridade da história do país e das empresas de construção. Em 2010, no auge dos despejos que marcou a crise financeira mundial, iniciada em 2007 - e que deixou bairros inteiros praticamente abandonados em todo o território dos EUA- mais de dois milhões de famílias foram despejadas ao longos dos anos de 2007 a 2013 devido ao fato de a maioria não ter quitado as dívidas hipotecárias. No Brasil, ao mesmo tempo, loteamentos horizontais e verticais começaram a ser construídos nas periferias das grandes e das médias cidades brasileiras. Uma das principais respostas do governo para a crise foi o lançamento do pacote habitacional Minha Casa Minha Vida, em abril de 2009, com a meta de produzir um milhão de moradias, com o objetivo de reduzir os danos causados pela crise de 2008.

Esses programas, além de proporcionarem acesso a dados que confirmam o crescimento econômico e do país, influenciam o aumento da indústria da construção civil, apesar de ainda não conseguirem resolver os problemas da precarização do trabalho e dos vínculos empregatícios que essas numerosas empresas poderão oferecer aos seus contratados. Esse aumento da rotatividade do capital e das empresas contratantes faz com que elas procurem as camadas sociais mais baixas, sempre objetivando o lucro e o crescimento do seu capital de giro, e propõem as mais diversas formas de acordo empregatício, inclusive os precários, que são aceitos por essa população devido à necessidade de sobreviver. Historicamente, a população estudada é composta de indivíduos provenientes das mais baixas camadas sociais brasileiras, que lutam muito mais para sobreviver do que para ter estabilidade financeira.

\section{Sentimentos provenientes da migração pendular} e do sofrimento mental

Segundo Bhugra (2001), o desenvolvimento individual, familiar e socioprofissional dos migrantes e a saúde física e psíquica dessas pessoas são afetados nesse processo, mesmo que a migração/imigração seja feita com um propósito bem definido, como é o caso da pendular.

estágio inicial de migração/imigração pode ter índices menores de doenças de cunho mental e de outros problemas de saúde, quando se compara com os estágios 
posteriores, o que é influenciado pela idade do trabalhador, por eventuais problemas de aculturação adquirido e por uma potencial discrepância entre a realização dos objetivos e as conquistas reais nos estágios posteriores (Brasil, 2010).

Eisenbruch (1991) enuncia que a perda da estrutura social e da cultura pode provocar uma reação de pesar. Frequentemente, o processo migratório, realizado dentro ou fora de determinado território, ocasiona a perda de atitudes culturais, valores, estruturas sociais e de redes de suporte, familiares e/ou sociais, incluindo a linguagem (especialmente a coloquial, os dialetos e/ou as gírias) Lindert, Ehrenstein e Priebe (2009) explicitam que o contato da comunidade migrante ou minoritária com comunidade nova ou dominante pode levar à assimilação, à rejeição, à integração ou à desculturação.

O luto cultural pode ser a primeira etapa na concretização do processo migratório. Eisenbruch (1991) ${ }^{17}$ definiu o luto cultural como uma experiência resultante da perda de estruturas sociais, de valores culturais da autoidentidade do indivíduo. Para Berry (1980), desculturação vivenciada por essas pessoas, através da perda de suas identidades culturais, a alienação por causa da falta de lazer e a apropriação dos equipamentos de cultura e estresse aculturativo podem levar ao etnocídio.

De acordo com Jardim e Lancman (2009), o mundo objetivo, com suas lógicas, desafios, regras e valores como a experiência da migração, por exemplo—entrará em conflito com a singularidade do trabalhador e fará com que o confronto entre relações e organizações do trabalho versus o mundo interno e subjetivo do trabalhador gere sofrimento psíquico.

Sob o ponto de vista de Debiaggi (2004), a crise identitária e discriminatória vivenciada em processos migratórios pode ser associada à saudade. Esse auto entende que a passagem árdua de uma cultura para outra e a falta de integração na sociedade de acolhimento podem levar o indivíduo a adoecer devido à experiência do luto cultural ou perda do referencial.

\section{MÉTOdo}

Em relação à forma de abordar o problema, esta pesquisa apresenta caráter quantitativo e qualitativo. É uma abordagem quantitativa, porque recorremos a um questionário com perguntas fechadas para traçar o perfil dos participantes, e qualitativa, porque utilizamos um roteiro semiestruturado, que sugere o uso do método de análise de conteúdo, baseado em um paradigma interpretativo de pesquisa. Quanto aos objetivos, trata-se de uma pesquisa de natureza descritiva e de campo, que se justifica quanto aos procedimentos técnicos utilizados.

Convém enfatizar que o roteiro semiestruturado não foi elaborado com a intenção primeira de averiguar sentimentos de saudade, porém esses sentimentos foram identificados como constantes nos discursos dos indivíduos, e isso justifica a necessidade de discussões mais profundas como a deste artigo.

Quanto aos procedimentos éticos, o projeto foi aprovado pelo Comitê de Ética e Pesquisa da Universidade Federal da Paraíba, CAAE: 17163613.0.0000.5188 protocolo $n^{\circ}$ 0318/13, que data de 10/03/2013. Os dados foram coletados em dois canteiros de obras de uma empresa de construção civil de João Pessoa/PB, no período de 18 a 27 de março de 2014, durante seis encontros.

Os trabalhadores foram convidados a vivenciar a pesquisa por meio do coordenador das obras, que identificou os que preenchiam o pré-requisito exigido para a pesquisa: morar em alojamentos cedidos pela empresa durante o período de trabalho. Foram recrutados 20 operários, dos quais 17 se dispuseram a responder a entrevista.

Os trabalhadores voluntários apresentavam-se e iniciávamos a explicação dos procedimentos éticos e uma explanação sobre os objetivos da pesquisa que viabilizavam a assinatura do termo de consentimento livre e esclarecido.

A população migrante, objeto de pesquisa deste estudo, é quase toda oriunda de Pilar, cidade cuja população, em 2013, era de 11.620 habitantes e com IDH 0,579, um dos mais baixos do estado da Paraíba. Essa característica explica o processo de migração vivenciado por esses adultos em idade produtiva (IBGE, 2014).

Dados do Instituto Brasileiro de Geografia e Estatística (IBGE) estimam que, em 2013, João Pessoa tinha uma população de 769.607 habitantes; em 2010, seu índice de desenvolvimento humano (IDH) era de 0,763 , com média de 0,658 . A Paraíba ocupa a $23^{a}$ posição no ranking dos estados brasileiros (IBGE, 2014).

Os alojamentos visitados são lugares desprovidos de limpeza, sem separação de cômodos e servem também como estoque para materiais de construção. Os colchonetes são dispostos de maneira a ocupar espaços disponíveis, e a casa se localiza exatamente ao lado da construção.

Depois de coletar os dados, transcrevemos as enrevistas por meio do método de análise de conteúdo qualitativa de Bardin (2006). As categorias ou temas foram definidos depois da análise dos relatos dos entre- 
vistados e passaram pelas etapas previstas no método. Através da utilização de uma grelha para organizar os relatos, categorizamos as informações e mencionamos os conteúdos que emergiram. A identificação desses conteúdos resultou na elaboração de quatro categorias, entre elas, os sentimentos de saudade vinculados ao trabalhador migrante. A identificação dessa categoria de análise proporcionou as reflexões deste presente artigo, devido à necessidade de explorar e de aprofundar as referidas questões.

Nesse âmbito, a literatura sobre saudade, qualidade de vida, saúde mental e migração é escassa. A partir de uma consulta à base de dados do Periódico Capes, obtivemos 184 trabalhos que discorrem sobre "saudade" e "qualidade de vida", e 75 que abordam os termos "saudade" e "saúde mental". Em uma análise geral dos títulos dos trabalhos mais relevantes, vimos que não há vinculação de pesquisas com a temática deste artigo. Isso significa que há a carência de discussões sobre o assunto e sobre o referido público-alvo na literatura científica brasileira. Em relação à busca a partir dos termos "saudade" $\mathrm{e}$ "migração", só encontramos apenas três trabalhos.

\section{Resultados do questionário sociodemográfico: perfil da população}

Para identificar o perfil do público-alvo, utilizamos o questionário sociodemográfico. Todos os entrevistados eram homens, com faixa etária de 19 a 54 anos e média de idade correspondente a 37 anos.

No quesito escolaridade, constatamos que $88,23 \%$ dos indivíduos têm alguma escolaridade, que varia entre ensino fundamental incompleto e ensino médio completo. A média de tempo de trabalho foi de $42 \mathrm{~h}$ semanais, o que corresponde a, aproximadamente, $8,4 \mathrm{~h}$ por dia. Isso demonstra a intensidade da atividade, visto que o trabalho é, em sua totalidade, de cunho braçal.

Apenas um dos entrevistados tem carteira assinada (salário de R\$2.000, o maior do grupo). Nota-se que o salário do grupo de trabalhadores desta pesquisa encontra-se, atualmente, abaixo da média do trabalhador brasileiro, que, em 2014, era de R\$2.026,60.

\section{Resultado E Discussões}

Várias das respostas nos mostraram que o vínculo com a família, antes e depois do trabalho atual, não foi alterado, porém esse tipo de resposta vem seguido de um discurso saudoso, que contradiz o primeiro argumento dos trabalhadores. "É a mesma coisa, trabalhando em casa, fora, são a mesma coisa. Mas saudade é a cada dia, né? Cada dia que você passa fora de casa você vai ter uma saudade" (T1, comunicação pessoal, novembro de 2016).

Assim, respostas curtas, como "Não, nenhuma"; "Não, não, continua tudo do mesmo jeito"; "Continua do mesmo jeito, o mesmo contato", que são referentes à pergunta: "Existem mudanças na sua relação familiar antes e depois da sua moradia nos alojamentos?", demonstram que o fato de os vínculos familiares estarem aparentemente preservados não significa necessariamente que os sujeitos não vivenciem sofrimentos provenientes da saudade.

Esse fato corrobora o estudo de Bongianino (2012) sobre os cabo-verdianos e seu processo de migração para a Itália. Ainda que seja possível contornar a ausência física, a distância não se dilui, tampouco perde a importância. Ela é vivida com dor e gera tensões, mas a sociedade cabo-verdiana lida com esses aspectos para que as relações emocionais e os vínculos afetivos não se rompam.

Não, não, não. Nunca tive essa diferença não. É a mesma coisa, trabalhando em casa, fora, são a mesma coisa. A saudade é a cada dia, né? A saudade é cada dia que você passa fora de casa, você vai ter uma saudade (T1, comunicação pessoal, novembro de 2016).

Outra perspectiva em relação à saudade é dada quando os indivíduos descrevem a falta da proximidade com a família, com os amigos e até com a comunidade religiosa, deixando explícito que isso é uma desvantagem no trabalho.

Fica mais distante, né? Mas é o jeito, né? A gente tem que fazer isso, se não fizer, vai fazer dentro de casa o quê? Sem trabalho, a pessoa não sobrevive. Se a pessoa não sair pra trabalhar, passa fome, que nem você bem vê (...) (T2, comunicação pessoal, novembro de 2016). 
Nesse contexto, a formação de "guetos" por parte dessa população se justifica, em algumas circunstâncias, por causa das dificuldades provenientes do processo de adaptação à terra de migração e à população local, po isso prefere se relacionar com os próprios colegas de trabalho. Segundo Borges e Martins (2004), repulsar o estrangeiro (tanto por parte do nativo quanto por parte do migrante na ocasião) é distanciar-se daquilo a que o outro o remete, sem a intenção de se conhecer a realidade daquela diferença. Essa resistência dificulta o desenvolvimento de capacidades adaptativas, como demonstrado neste trecho: "(...) é perigoso demais, aqui na capital né, a gente sair... só é do serviço pra o alojamento e do alojamento pra casa nos finais de semana." (T5, comunicação pessoal, novembro de 2016).

Nota-se, ainda, a dificuldade de separar a nova casa do ambiente de trabalho. Essas duas localizações se fundem de maneira que é difícil falar sobre uma sem referencia a outra. Esse fato, porém, não faz com que o trabalhado identifique o alojamento como sua casa: "Vou pra casa (errou a palavra e retificou), vou pro alojamento. Não considero casa o alojamento, né? (...)" (T4, comunicação pessoal, novembro de 2016).

Segundo Freud (1920), o luto (ou o sentimento de saudade do "objeto" perdido) pode desencadear melancolia em algumas pessoas. Esse fenômeno não pode se descrito como patologia. Quanto às perdas transitórias, Klein (1971) afirma que a luta contra o medo da perda (um abandono, luto, um distanciamento ou até mesmo a morte do "objeto" amado) desequilibra o mecanismo psíquico. Entretanto, isso não pode ser comparado com a melancolia, que, segundo os autores, é uma neurose obsessiva.

Entendemos, então, que os trabalhadores sinalizam sentimentos de saudade pelos referenciais da cidade natal, pela família, por grupos sociais, como os da igreja pela falta do ambiente físico e pelos objetos utilizados na cidade natal. Esses aspectos são indicadores da vivência de luto (distanciamento ou perda do "objeto" amado) como mostram estas falas:

Agora sente muita falta da família e, principalmente, da igreja (T10, comunicação pessoal, 2016).

(...) meu lazer é pegar "meus filho" e tomar um banho no rio. Agora, aqui, não tem muito lazer não, não tem muito o que fazer aqui não (T6, comunicação pessoal, novembro de 2016).
É ruim por uma parte porque em casa é outra coisa, né? Mais diferente, né? Aqui a gente dorme de todo jeito, coloca um colchonete no chão e dorme (T5, comunicação pessoal, novembro de 2016)

Alojamento é cada um por si, né? No alojamento a gente que faz a comida e na minha casa é minha esposa que faz a comida e põe no prato, e a gente faz e põe no prato da gente, aí já é uma diferença, né? (T14, comunicação pessoal, novembro, 2016).

Porém, devido a limitações do método de coleta e de análise de dados, não é possível, a partir das entrevistas, apontar a evolução dos sentimentos de perda para situações de melancolia, depressão ou outra psicopatologia mesmo que os próprios sentimentos de perda, segundo os autores explicitados, sejam geradores de desequilíbrio dos mecanismos psíquicos.

Quanto à adaptação à nova cultura, é nítida a resistência dos trabalhadores para se ambientarem e reconhecerem o alojamento como sua "nova" casa. Isso corrobora o que foi dito anteriormente sobre se distanciar de tudo o que é "novo" ou "estrangeiro".

Tem cama, mas ninguém num armou não, é ruim demais de armar as camas. Tem muita gente que armou, mas tem muitos que dormem no colchonete. Lá tem dois quarto, cada um quarto fica duas pessoas, três... fica no corredor. (T5, comunicação pessoal, novembro de 2016).

Os relatos dos trabalhadores demonstram que há um distanciamento da realidade voltada para o contexto para onde migraram. Os pesquisadores presenciaram discursos que se assemelhavam a perdas irrecuperáveis, relacionadas ao desenrolar do crescimento dos filhos, demonstrando, por exemplo, o impacto das mudanças nas relações familiares ao longo do tempo de trabalho.

Relação familiar, a gente sente muito a falta né? Porque a gente tá muito apegado aos filhos e não vê muito crescer, porque só chega no fim de semana e rapidamente volta e, quando vê, eles já tão grandinho vão crescendo e a gente não, não sabe nada da vida deles (T8, comunicação pessoal, novembro, 2016). 
Quanto às justificativas dos trabalhadores para continuarem o processo de migração pendular, com base nas notas de campo, notamos que os silêncios, as pausas nos depoimentos e as reações emocionais (como o choro durante as entrevistas) são equilibrados com a sensação do papel de "provedor" financeiro desse trabalhador, que auxilia a perpetuar os desafios de viver como minoritários em uma terra desconhecida. Tal sensação pode ser apontada como o motivo pelo qual o sentimento de luto e de perda transitória do objeto - explicitado pela Psicanálise - não induza ao desenvolvimento de melancolia ou de neuroses nesse grupo de trabalhadores.

A vantagem que tem é que a gente tá ganhando o dinheiro da gente né, que interessa a gente. E a desvantagem é que a gente tá longe de casa, mas, tem a vantagem da gente que é o dinheiro né, só (T3, comunicação pessoal, novembro de 2016).

Os fatores pessoais, ambientais, psicossociais, bem como a saúde e a doença se relacionam na interpretação do indivíduo e determinam de que maneira e o quanto ele valoriza e se sente satisfeito com sua vida e suas escolhas. Essa satisfação dependerá da sensação de prazer e de falta de sofrimento e terá como contribuição esperança, visão de futuro, significado, persistência e autoeficiência (Campos \& Lobato, 2005).

\section{CONCLUSÕES}

Nesta pesquisa, a saudade foi caracterizada como um fator ligado à vivência de sentimentos de luto e perda transitórios e às dificuldades de os entrevistados se adaptarem à cultura local. Esse é um fator sugestivo a desequilíbrios nos mecanismos mentais. Segundo os trabalhadores, o processo ora fragmentou seus vínculos familiares e afetivos - devido à distância - ora não foi tão significativo, por causa do recebimento do salário. Depois de fazer essa análise, compreendemos que as condições gerais de vida dos trabalhadores que participaram deste estudo sofreram e sofrem alterações com o desenvolvimento de uma atividade de trabalho que implica a migração pendular.

Este estudo possibilitou reflexões acerca dos discursos saudosos dos trabalhadores e suas vinculações a possíveis danos à qualidade de vida e à saúde mental. Conclui-se que, apesar da identificação do sentimento de luto; da perda transitória e da resistência para se adaptar a uma nova cultura, as situações melancólicas ou o aparecimento de psicopatologias não podem ser identificadas no contexto pesquisado devido a limitações do método nem foram idealizadas como objetivo da pesquisa. Entretanto aspectos relacionados à opinião de migrantes pendulares têm sido pouco considerados no processo de desenvolvimento de pesquisas científicas. Como agenda de pesquisa, sugerimos que este estudo continue com diversas realidades no município e em outros estados da Federação, tendo em vista a prejudicial situação em que estão inseridos os trabalhadores da construção civil, que foi comprovada pelos dados apresentados.

Considerando que a terapia ocupacional é capaz de promover mudanças no cenário de vida e na rotina desses migrantes, neste estudo, propusemos algumas possíveis reflexões e intervenções no campo, com o objetivo de evitar os processos de adoecimento mental supracitados, como: mapeamento de dispositivos sociais; oficinas com enfoque na promoção da saúde e prevenção de agravos desses trabalhadores e execução de atividades em grupo por meio das quais possam externalizar sentimentos.

Tais processos interventivos objetivam minimizar o sofrimento proveniente do sentimento de saudade de casa durante o tempo alojado e auxiliar o abandono da postura de "outsider" do grupo entrevistado. A viabilização do acesso aos dispositivos sociais da cidade onde executam o trabalho como operários de obra tem a finalidade de que o indivíduo se aproxime da nova cultura e lide, de forma criativa, com a saudade proveniente da distância ou do luto transitório.

Como recomendação, sugerimos que os gestores e os stakeholders incluídos no setor da construção civil voltem mais sua atenção para as subjetividades do trabalho do operariado, principalmente dos migrantes. A preocupação com as condições de moradia, com a inserção social e com o desenvolvimento do sentimento de pertencimento ao local de trabalho deve ser considerada para beneficiar a saúde do trabalhador e seu desempenho na empresa com o fim de evitar o agravamento de situações de perda e luto transitório, para situações de melancolia, sofrimento profundo e afastamento do trabalho.

Para isso, é necessário empregar estratégias como a inclusão de equipes multiprofissionais de saúde no canteiro de obras ou consultorias que viabilizem informações para os gestores acerca das situações de risco físico e psíquico às quais são submetidos os trabalhadores com o perfil em questão. 


\section{REFERÊNCIAS}

Andrade, P. S, \& Cardoso, T. A. O. (2012). Prazer e dor na docência: revisão bibliográfica sobre a síndrome de Burnout. Saúde Soc. São Paulo, 21(1), p.129-140

Assis M. D, Franken I., Meneses A. C. B. S, \& Oliveira T. M (2013). Adaptação à universidade no processo de migração e sofrimentos psíquicos. In: Encontro de Extensão, 2013, João Pessoa.

Bardin L. (2006). Análise de conteúdo. 2 ed. Lisboa: Edições 70.

Berry J. W. (1980). Acculturation as varieties of adaptation. In: Padilla AM (ed.). Acculturation. Boulder: Westview, pp.9-26

Bhugra D. (2001). Acculturation, cultural identity and mental health. In Bhugra D, Cochrane R (eds). Psychiatry in multicultural Britain. London: Gaskell, pp.112-36.

Bhugra D., \& Becker M. (2005). Migration, cultural bereavement and cultural identity. World Psychiatry; 4, pp. 18-24.

Bongianino C. F. (2012). Malas de sonhos e saudade: família e mobilidade entre cabo-verdianos na Itália. MÉTIS: história \& cultura. 11(22 pp. 257-280.

Borges H, \& Martins A. (2004). Migração e sofrimento psíquico do trabaIhador da construção civil: uma leitura psicanalítica. PHYSIS: Rev Saúde Coletiva, Rio de Janeiro, 14(1), p. 129-146

Branco M. L. C, Firkowski O. L. F, \& Moura R. (2005). Movimento pendular: abordagem teórica e reflexões sobre o uso do indicador. $X$ Encontro Nacional da Associação Nacional de Pós-graduação em Pesquisa e Planejamento Urbano e Regional - ANPUR, Salvador de 23 a 27 de maior de 2005 (CD-ROM).

Brasil. (2013). Anuário Estatístico da Previdência Social. Brasília: Secretaria de Políticas de Previdência Social. 21, p. 529-530. Disponível em $<$ http://www.renastonline.org/recursos/aeat>. Acesso em: 15 de agosto de 2015

Brasil. (2010). Comunicados do IPEA: Migração interna no Brasil. Disponível em: http://www ipea govbr/portal/images/stories/PDFs/comunicado/100817 comunicadoipea61.pdf. Acesso em 17 de jul. 2014.

Canha J. I. E. (2009). Adaptação, saudades de casa e sintomatologia depressiva nos estudantes deslocados. 40 f. Dissertação (Mestrado Integrado em Psicologia) - Universidade de Lisboa - Faculdade de Psicologia e de Ciências da Educação, Lisboa.

Debiaggi S. D, \& Paiva G. J. (Orgs.) (2004). Psicologia, e/imigração e cultura. São Paulo: Casa do Psicólogo.

Eisenbruch M. (1991). From post-traumatic stress disorder to cultural be-reavement: diagnosis of Southeast Asian refugees. Soc Sci Med 33, pp. 73-80

Freire I., Renato C., \& Tavares M. F. L. (2005). A saúde sob o olhar do idoso institucionalizado: conhecendo e valorizando sua opinião. Interface (Botucatu) [Internet]. Fev [citado 2016 Ago 10]; 9 ( 16 ): 147-158. Disponível em: http://www.scielo.br/scielo.php?script=sci_arttext\&pid=S1414-32832005000100012\&lng=pt. http://dx.do org/10.1590/S1414-32832005000100012
Freud S. Luto e melancolia in: Obras completas de Sigmund Freud. vol. XIV. Rio de Janeiro: Imago, 1920

Hunger D, Rossi F, \& Souza N. S. (2015). A teoria de Norbert Elias: uma análise do ser professor. Educação e pesquisa, 37(4), 697-710. Retrieved october 30. Avaiable from: http://www.scielo.br/scielo.php?scrip$\mathrm{t}=$ sci_arttext\&pid=S1517-97022011000400002\&lng=en\&tlng=pt.

Instituto Brasileiro de Geografia e Estatística (IBGE). Censo Demográfico 2014: cidades. Avaliable from:: http://cod.ibge.gov.br/233A1. Acesso em: 03 jun. 2014

abur P. A. C, Campos IO, Souza TR, \& Paula LB. (2015). Migração e situações de rua: o uso do álcool nas ruas de Brasília. Cadernos de Terapia Ocupacional da UFSCar. 2014; 22 (SE):125-133. DOI http:// dx.doi.org/10.4322/cto.2014.037

ardim T. A. \& Lancman S. (2015). Aspectos subjetivos do morar e trabalhar na mesma comunidade: a realidade vivenciada pelo agente comunitário de saúde. Interface (Botucatu) [Internet]. 2009 Mar [cited 2015 Oc 29] ; 13 ( 28 ): 123-135. Available from: http://www.scielo.br/scielo. php?script=sci_arttext\&pid=S1414-32832009000100011\&lng=en http://dx.doi.org/10.1590/S1414-32832009000100011.

Klein M. (1971). O sentimento de solidão. Imago: Rio de Janeiro, 1971.

Lindert J. Ehrenstein S. \& Priebe S. etal. (2009). Depression and anxiety in labor migrants and refugees - a systematic review and meta-analysis. Soc Sci Med;69, pp. 246-57.

Noriega, J. A. V. (2009). Depresión, ansiedad y estrés en niños y niñas jornaleros agrícolas migrantes. Psico, Porto Alegre, PUCRS, v. 40, n. 3, pp. 337-345, jul./set.

Pussetti, C. (2010). Identidades em crise: imigrantes, emoções e saúde mental em Portugal. Saude soc. IInternet]. Mar [cited 2015 Oct 28 19(1): 94-113. Available from: http://www.scielo.br/scielo.php?script=sci_arttext\&pid=S0104-12902010000100008\&Ing=en. Doi http://dx.doi.org/10.1590/S0104-12902010000100008.

Six F. (2007). A construção: o canteiro de obras no centro do processo de concepção-realização. In: Pierre Falzon. Ergonomia. São Paulo: Blucher. pp. 557-72. 
Contato: Barbara Barroso, +55 (83)- 99922-2529. Endereço: Centro de Ciências da Saúde, Departamento de Terapia Ocupacional, $2^{\circ}$ andar, Laboratório de Saúde, Trabalho e Ergonomia (LASTE). Universidade Federal da Paraíba, Campus Universitário I, Bairro: Cidade Universitária CEP: 58059-900, João Pessoa-PB.

Artigo inédito elaborado a partir de dados coletados durante pesquisa contemplada pelo Programa Institucional de Bolsas de Iniciação Científica (PIBIC), com vigência 2013-2014 e número interno 23074.043466/13-66, que financiou o estudo através do Laboratório de Saúde, Trabalho e Ergonomia (LASTE), na área de concentração: Psicodinâmica do Trabalho, Universidade Federal da Paraíba. Orientado pela Professora Barbara lansã de Lima Barroso. Este estudo é parte de uma pesquisa feita com seres humanos e aprovada pelo Comitê de Ética em Pesquisa do Centro de Ciências da Saúde (CCS), com o número do Certificado de Apresentação para Apreciação Ética (CAAE) 17163613.0.0000.5188. 